\title{
Personnel management in the sustainable transport and logistics industry
}

\author{
Katarína Hercegová ${ }^{1, *}$, Alexander Pyanov² and Oksana Mukhoryanova ${ }^{2}$ \\ ${ }^{1}$ Prague Business School, Werichova str. 1145/29, 15200 Prague, Czech Republic \\ ${ }^{2}$ North Caucasus Federal University, Pushkin str., 1, Stavropol, 355009, Russian Federation
}

\begin{abstract}
This paper describes the methods and techniques of the ways personnel security is ensured and maintained in the sustainable transport industry. In addition, it focuses on the novel methods and technologies used by the human resource managers for selecting and hiring candidates for jobs in the transport and logistic sector. Furthermore, it gives a comprehensive overview of human capital management in the transport industry and provides a detailed analysis of several segments covered. It offers a detailed insight into the growth markets and their impact on the human resource management market in the transport industry. Our results demonstrate that the majority of the world's largest transportation and logistics companies believe that data-driven decision-making is essential to supply chain activities and is hiring the right employees. The paper shows that this datadriven approach might be the best solution for optimizing performance and achieving the standards of sustainable and environmentally-friendly business both at the personnel level and at the level of operation and efficient management. Moreover, it stresses the importance of the artificial intelligence and deep learning in the development of the sustainable transport industry.
\end{abstract}

\section{Introduction}

Logistics solutions include truck transport, logistics, transport and logistics services as well as logistics solutions for the transport industry. The largest global logistics and transport companies specializing in IT-based solutions for the transportation and logistics industry provide domestic and international air and sea freight and logistics services for commercial, industrial and commercial passenger and freight transportation [1, 2]. Providing national, international and air freight to ocean freight services, logistics and supply chain management services can be a complex business that requires lots of data to collect and to process. This data needs to be constantly analysed for any useful patterns in order to improve the quality of the services. In order to deal with this challenge, GlassWing, an Indian start-up, offers a high-tech solution for the transport and logistics industry in India. The Glass Wing platform forms the backbone of a logistics service network that connects freight owners with transport companies. Developed in collaboration with the Indian Institute of Technology, Bangalore and the University of Hyderabad. The start-up also helps to reduce freight costs by using

\footnotetext{
*Corresponding author: hercegova@pbs-education.cz
} 
artificial intelligence (AI) and provides tailored reports, data analysis and analysis for freight management and logistics [3].

Today, the logistics and supply chain sector are under increasing pressure, given the shifting interest in products and a variety of personalised services. Logistics service providers can quickly adapt to changing sales needs. AI and machine learning to optimize supply chain routing and integrate data analysis and analysis into logistics management systems [4]. We can use multiple transport and logistics networks to deliver goods and services faster, more efficiently and more cost-effectively. In addition, it is possible to take advantage of the advantages of rail networks as a key component of logistics and supply chain management systems for high-tech companies [5].

On the one hand, high-tech products are very attractive to thieves, so it is vital to protect them throughout the supply chain [6]. Additionally, smart solutions are changing the way goods are transported around the world, and analytics are creating more efficient supply chains. The industry knows this, and the majority of executives believe it will have a disruptive force that can change the industry forever. The world's largest companies are integrating technology-driven, data-driven solutions to make their transportation and logistics operations more efficient and cost-effective [7].

According to a recent report by the International Logistics Association (ILA), shippers, freight forwarders, suppliers and consumers can benefit from the trends in logistics technology continuing into the 2020s [8]. With this flexibility in mind, high-tech transport and logistics companies, such as logistics technology companies, offer a wide range of transport solutions for freight, freight forwarders, suppliers and consumers. These companies offer specialised transit options for both freight and freight and destination (FTT) transport as well as freight transport services. They use several freight routes, including air, sea, rail and road. They also offer their customers, suppliers and supporters less than truckloads and provide cost-effective, effective local knowledge. The privately held family business generates high profits in annual revenue. The non-asset-oriented companies specialises in time-critical logistics and transport business.

\section{Sustainable transport and travel sector}

From this perspective, an efficient and flexible transport system that offers intelligent and sustainable mobility patterns is essential for health, the economy and living standards. Current transport systems are a growing challenge to the sustainability of the economy, society and the environment in general [9]. Current mobility programmes are becoming increasingly dependent on private vehicles, which determine the lifestyle and design of citizens' cities. As the world's urban population continues to grow, especially in developing countries, there is an urgent need to develop the infrastructure that supports world trade. Transport is a major driver of economic growth and its linkage with other sectors such as energy, energy efficiency, transport infrastructure and the environment. In urban areas, the challenge is to expand and improve the transport supply so that cars and lorries have an alternative. This can be achieved by developing public transport infrastructure by improving existing public transport and making transport more efficient and cost-effective - for all users, not just the wealthy $[10,11]$.

However, according to a recent report by the European Commission, automation of vehicles seems to be an even more effective tool to enable the use of existing vehicles and road vehicles and to reduce the number of vehicles in circulation. This, together with an aging world population and a reduction in the number of cars on the roads, will reduce the need for car ownership. By $2030,40 \%$ of all journeys in cities will be environmentally friendly, compared to $51 \%$ of journeys currently made by car. This decline is offset by increased use of public transport as citizens switch to more environmentally friendly means of transport. 
The remaining 5\% will be made up of the majority of private vehicle journeys such as buses, trains, taxis and buses [12]. In a market where domestic kerosene is not subject to carbon pricing, this will help to create a level playing field for less energy-intensive forms of transport. In response to the crisis of COVID-19, the French government has announced a sustainable mobility package that includes incentives for workers to demonstrate their commitment to sustainable modes of transport such as car sharing and cycling. The accelerated phase - the fossil-fuel phase-out and the persistently low cost of renewable energy sources such as wind and solar - are key factors in increasing the use of sustainable transport and travel in cities and communities. In the wake of the COVID-19 crisis, the government is now pursuing interventions that would completely remove cheap, energy-intensive options from travellers' decision-making. If passengers choose to take the train instead of driving, they are considering choosing the more environmentally friendly option [13, 14].

The transport industry often concludes that passengers are not prepared to change their behaviour, which means more costs and time to reduce their environmental impact. But how can we make climate change a major part of our decisions, thereby helping to reduce carbon dioxide emissions? The reductions in recent years are due to a combination of better planning, better technology and more efficient use of resources. These factors contribute significantly to explaining the fluctuations in the energy intensity of the sector, reflected in the gross domestic product (GDP) that has been the main driver of global greenhouse gas emissions in recent years. Energy intensity in transport has increased in recent decades, with increasing energy consumption and the increase in vehicle use linked to increasing mobility and the level of vehicle use. Over $72 \%$ of the European population lives in urban areas, which are crucial for job growth, with a significant proportion of this population living in Europe's urban centres. Cities need efficient transport systems to support their economies and the wellbeing of their inhabitants, as well as to ensure long-term health and environmental wellbeing. There are 94 cities worldwide that are driving urban action to reduce greenhouse gas emissions and climate risks while improving the health and well-being of their urban citizens. To meet projected mobility and freight demand and reverse growth in $\mathrm{CO}_{2}$ emissions, the most effective strategies to reverse growth in $\mathrm{CO}_{2}$ emissions must be used as effectively as possible $[15,16]$.

Today, urban areas face the challenge of making the transition to a more sustainable transport system and economy while taking social concerns into account, the report says. Support active modes of transport such as cycling, which offer significant social, environmental and economic benefits. Support the transition to a more sustainable transport and travel sector, including the use of more efficient and sustainable means of transport, especially in urban areas. Governments must provide adequate incentives to ensure a sustainable recovery of the transport sector. As a result, governments can influence transport behaviour that becomes permanent after a crisis and benefits citizens in the long term.

\section{Human capital management in sustainable transport industry}

Human resources managers rely heavily on managers and managers to help plan and implement strategies, but they cannot do it alone [17]. Leadership and purchasing power are factors to consider when analysing the structural environment of an industry with the Porter's 5-force framework, whether any company plans to hire people who "help manage things" or need communication skills. For an organization to acquire its products and services, it must use the purchase and sale of resources to implement its plans, according to Porter. The first step in human capital management in the transport sector is to define common objectives and provide feedback on the results [18]. The Human Resources department is a leader and is to develop the strategy of the company through a combination of human capital management and total quality management (manager types and vertical management). Total quality 
management is its core value, which focuses on continuous improvement of the quality of products, services and quality processes, such as types, human-manager and vertical management. Some companies such as Whole Foods Market focuses on selling the highest quality products and services, such as organic, natural and organic-friendly products. Strategic processes are important to guide the overall marketing effort, ensure that they reach the right audience and help us keep a watchful eye on our goals and objectives [19].

There is a need for a comprehensive analysis of the impact of different business models, strategies and strategies of different companies, with a greater focus on the role of the human resources manager in the management of human capital management in the transport sector. The segments examined in this article are intended to examine the impact of human capital management in the transport sector on the growth of the human capital management market in the transport sector. First and foremost, one needs to identify the impact of human capital management in the transport sector on the expected impact on global industry. Many studies on human capital management suggests that the scale of the use of these techniques and the enormous resources available suggest that we are making critical judgments for readers about their understanding of the potential of this new technology and its potential impact [20]. There is also the need to adapt and maintain the leading markets for human capital management in Europe, North America, Asia-Pacific and Latin America. COVID-19 will affect the global economy by creating supply chain turbulence, directly influencing production and demand, and having an economic impact on business and trading markets.

In the field of human capital management, the supply and demand factors that shape the market and assesses the market conditions that influence it are crucial. Based on the potential of each segment, market participants and key manufacturers can better develop effective growth and appropriate business decisions. This is very well-explained by the human capital management market analysis that cover the social, political, economic and technical factors affecting various markets [21, 22]. A detailed analysis of trends in human capital management in the transport sector and its impact on leading companies and shareholders is also needed to grasp these trends. Human capital management market research focuses on the leading industry leaders and the institutions that provide these products and services. They present an in-depth analysis of the human capital management market in the transport sector and offers perspectives for important business developments. The aim of this global research reports is to present consumers with data on the global market for human capital management in the transport sector in the coming years. The continuation of the information in these reports also includes the advertising essays of the market leaders and their marketing strategies. The reports are complemented by a comprehensive analysis of human capital management in the transport sector [23].

Therefore, in today's complex work environment, there are seven ways in which companies can deliver a profitable experience that leads to better results. The Employee Experience Gap study found that more than $80 \%$ of respondents in the United States and Europe believe that employee experience will be one of the most important factors in helping to achieve business objectives within two years. Moreover, the study shows that this is why in 2021 it can be given a forecast of 3.5\% annual growth for the transport sector [24]. Overall, it appears that creating a continuous feedback loop between employees and staff not only changes the experience of employees, but also drives resilience and improvement of business results over time.

\section{Novel technologies used by the HR managers in transport and logistics}

Novel and IT-driven technologies are very popular with managers and recruiters when it comes to finding the right candidates for their respective jobs. When companies use 
technology to collaborate, they are considered the best in class when it comes to ensuring that their human resources teams manage the recruitment process, from evaluating candidates, exchanging feedback, to making hiring recommendations [25]. Companies also rely on technology, as it allows them to monitor employee performance and track sources of hiring to target the "right" candidates through the right channels. However, the importance of technology to prevent bias in the recruitment process for candidates has also recently been highlighted. The introduction of automated recruitment tools gives recruiters time to evaluate candidates at a deeper level and improves the company's ability to deliver high-quality hiring over the long term [26].

According to one recent study, the majority of candidates apply to companies without having a positive first experience with the job interview. Gaps in candidate experience can transform a highly qualified candidate into a less-than-ideal candidate for a particular position, such as a part-time job. Alternatively, the experience gained with the candidates can also be used as a promoter for repeat applicants [27]. Simple automation of candidate communications can significantly improve the experience of potential employees with the company and encourage them to join the team. Recruiters and HR managers receive a lot of praise for the changes that have been brought about by the introduction of technology into the recruitment process. From finding the best people to enabling automated processes and accessible data management, information technology is revolutionary in recruiting and hiring companies like Google, Facebook, and Microsoft. By progressively implementing these advances, companies can save time and money in the recruitment process.

The job candidate tracking systems are designed to ensure effective recruitment management and allow recruitment agencies to keep an eye on applicants while managing other stages of the recruitment process. With these systems, recruiters have a better understanding of the process of sourcing and hiring the right talent. These systems can help improve the overall recruitment process and facilitate the work of the recruitment officer while creating a more effective workforce. As a result of this shift, job seekers should not only expect video interviews to be standard or that the hiring process has taken much longer lately. Given these advantages, recruiting software is a good choice for companies that want to improve their recruitment and recruitment processes and practices. It helps recruiters find the best talent, shortens recruitment cycles, ensures good candidates and onboarding processes, and helps make recruitment more efficient [28].

Various talent acquisition platforms that automate the application process by scanning applicants' CVs for specific skills and experience, as well as intelligent word processing tools that facilitate recruitment and communication during the recruitment process, are also on the rise. One should also expect to interact with artificial intelligence - powered tools, such as software programs, that are intelligent enough to pass them on to people who can screen candidates, ask questions about interviews, and answer questions that candidates may have more frequently. While COVID-19 influence is also slowly waning, this change in recruitment practices continues to resonate with recruiters. Not to mention that automation tools sourced from platforms such as LinkedIn and video interview platforms enable recruiters to offer candidates an enhanced experience during the interview. In addition, support for the end-to-end life cycle can be offered to guide candidates through interviews and their time for professional advancement.

Here are just some of the key ways technology is changing the way recruitment works today. The technology makes it easier for companies to find qualified candidates from all over the world. Recruits can turn to global candidates if they cannot find specific skills locally. Business companies can search for candidates worldwide, which makes the pool of candidates larger and more diverse. According to a recent survey by the United States Chamber of Commerce, $84 \%$ of recruiters have adjusted their hiring process to facilitate long-distance calls. While almost half of the service's advertisements have increased to 
advertise vacancies, $58 \%$ have also used it to connect with potential new hires. While $55 \%$ of recruiters also use telephone calls to get potential recruits, a way to connect with candidates has been introduced in recent years [29]. A growing army of recruiters has also turned to video to film and interview candidates, and as many as 8 in 10 now make video conferencing a key element of the recruitment process [30]. This trend has led some recruiters to use video interview technologies and low-cost services such as Skype, Zoom, or MS Teams, just to name a few solutions most widely-used nowadays.

\section{Conclusions}

In the recent years, the transport and logistics industry has begun to employ many advanced technological solutions for hiring, training and managing its personnel. Teleconferencing, social networks, interactive learning and monitoring can help a lot in sustaining high-quality employees. Moreover, it also started to integrate artificial intelligence solutions, including machine learning, artificial intelligence and deep learning, into its business operations, and this is just the beginning. In addition, these advanced technological solutions have already made a huge difference in logistics, from automated pick-up systems to logistics management systems. Therefore, artificial intelligence and deep learning can clearly play an important role in the development of the sustainable transport industry.

Our results demonstrate that data-driven approach applied to managing human resources in the sustainable transport and logistics industry might be the best solution for optimizing performance and achieving the standards of sustainable and environmentally-friendly business both at the personnel level and at the level of operation and efficient management.

\section{References}

1. E. Hofmann, F. Osterwalder, Logistics, 1 (2), 9 (2017)

2. W. Strielkowski, T. Veinbender, M. Tvaronavičienè, N. Lace, Economic researchEkonomska istraživanja, 33 (1), 788-803 (2020)

3. Startus Insights (2021). Access mode: https://www.startus-insights.com/innovatorsguide/top-10-logistics-industry-trends-innovations-in-2021

4. Y. Gruzina, I. Firsova, W. Strielkowski, Economies, 9 (2), 67 (2021)

5. R. Dubey, T. Singh, AIMS International Journal of Management, 3 (3), 191-205 (2009)

6. A. Sarac, N. Absi, S. Dauzère-Pérès, International journal of production economics, 128 (1), 77-95 (2010)

7. N. Agarwal, Innovation landscape in developed and developing markets: a conceptual and empirical study on technology convergence and low-cost innovations (2016)

8. Globe Newswire (2020). Access mode: https://www.globenewswire.com/newsrelease/2020/12/02/2138171/0/en/Global-Digital-Freight-Forwarding-Market-2020-to2025-Growth-Trends-and-Forecasts.html

9. P. Jiang, X. Fu, Y. Van Fan, J. Klemeš, P. Chen, S. Ma, W. Zhang, Journal of Cleaner production, 279, 123673 (2021)

10. E. Lisin, W. Strielkowski, Transformations in Business \& Economics, 13 (2B), 566-580 (2014)

11. B. A. Azevedo, L. F. Scavarda, R. G. Caiado, Journal of Cleaner Production, 233, 1377$1386(2019)$ 
12. European Commission (2021). Access mode: https://digitalstrategy.ec.europa.eu/en/policies/cam

13. IISD (2020). Access mode: https://www.iisd.org/sustainable-recovery/news/frenchstimulus-package-about-e30-billion-for-green-recovery-measures

14. S. Griffiths, D. F. Del Rio, B. Sovacool, Policy mixes to achieve sustainable mobility after the COVID-19 crisis, Renewable and Sustainable Energy Reviews, 143, 110919 (2021)

15. M. Simionescu, W. Strielkowski, M. Tvaronavičienè, Energies, 13 (9), 2280 (2020)

16. L. Penco, E. Ivaldi, C. Bruzzi, E. Musso, Cities, 96, 102443 (2020)

17. Y. Doz, Human Resource Management Review, 30 (1), 100693 (2020)

18. T. Poorani, S. Thiyagarajan, Technology in Society, 55, 160-165 (2018)

19. Investopedia (2019). Access mode: https://www.investopedia.com/articles/companyinsights/092816/how-sustainable-whole-foods-competitive-advantage-wfm.asp

20. A. Ferraris, A. Mazzoleni, A. Devalle, J. Couturier, Management Decision, 57 (8), 1923 1936 (2019)

21. O. Glazar, W. Strielkowski, Prague Economic Papers, 3, 218-235 (2010)

22. W. Strielkowski, S. Kalyugina, O. Mukhoryanova, Management Research \& Practice, 11 (3), 41-51 (2019)

23. Market Watch (2020). Access mode: https://www.marketwatch.com/pressrelease/covid-19-impact-on-human-capital-management-hcm-in-smb-market-sharesize-insights-2021-movements-by-key-findings-industry-impact-latest-trend-analysisprogression-status-revenue-expectation-to-2025-research-report-by-industry-researchbiz-2021-03-16

24. EY (2020). Access mode: https://www.ey.com/en_us/workforce/is-the-employeeexperience-you-are-delivering-the-one-your-people-want

25. T. Davenport, The AI advantage: How to put the artificial intelligence revolution to work (2018)

26. P. Van Esch, J. Black, J. Ferolie, Computers in Human Behavior, 90, 215-222 (2019)

27. A. Matraeva, M. Rybakova, M. Vinichenko, A. Oseev, N. Ljapunova, Universal Journal of Educational Research, 8 (1), 8-16 (2020)

28. L. Lepistö, E.M. Ihantola, Qualitative Research in Accounting \& Management, 15 (1), 104-123 (2018)

29. World Economic Forum (2020). Access mode: https://www.weforum.org/agenda/2020/06/coronavirus-advertising-marketingcovid19-pandemic-business

30. H. Zhao, Q.H. Zhao, B. Ślusarczyk, Sustainability, 11 (17), 4717 (2019) 